\title{
Lanthanide complexes with a tripodal nitroxyl radical showing strong magnetic coupling
}

\author{
Mauro Perfetti, ${ }^{\#}$ Andrea Caneschi, ${ }^{\perp}$ Taisiya S. Sukhikh ${ }^{\S}$ and Kira E. Vostrikova ${ }^{\$ *}$ \\ \# Department of Chemistry U. Schiff, University of Florence and INSTM Reseach Unit. Via della Lastruccia 3-13, \\ Sesto Fiorentino 50019, Firenze (IT). ORCID: 0000-0001-5649-0449 \\ ${ }^{\perp}$ Dipartimento di Ingegneria Industriale - DIEF, Università degli Studi di Firenze, INSTM Research Unit of Firenze, \\ Via di Santa Marta n. 3, Firenze - 50139, Italy. \\ ${ }^{\$}$ Nikolaev Institute of Inorganic Chemistry, Siberian Branch, Russian Academy of Sciences, 630090 Novosibirsk, Rus-
} sia.

A series of isomorphous mononuclear complexes of $\mathrm{Ln}(\mathrm{III})$ ions comprising one stable tripodal oxazolidine nitroxyl radical were obtained in acetonitrile media starting from nitrates. The compounds, [LnRad( $\left.\left.\mathrm{NO}_{3}\right)_{3}\right](\mathrm{Ln}=\mathrm{Gd}, \mathrm{Tb}, \mathrm{Dy}, \mathrm{Tm}, \mathrm{Y} ; \mathrm{Rad}=4,4$-dimethyl-2,2-bis(pyridin-2-yl)-1,3-oxazolidine-3-oxyl), have molecular structure. Their coordination polyhedron, $\mathrm{LnO}_{7} \mathrm{~N}_{2}$, can be described as a tricapped trigonal prism with symmetry close to $D_{3 \mathrm{~h}}$. The value of $23 \mathrm{~cm}^{-1}$ for the antiferromagnetic coupling Gd-Rad established from the $D C$ magnetic and EPR data is a record strength for the complexes of 4 f-elements with nitroxyl radicals. The terbium derivative displays frequency-dependent out-of-phase signals in zero field indicating single-molecule magnetic behavior with an effective barrier of $57 \mathrm{~cm}^{-1}$.

Lanthanides, complexes, organic radical ligands, oxazolidine nitroxyl radical, heterospin systems, magnetic properties, molecular magnetism, SMM, strong magnetic coupling.

\section{INTRODUCTION}

Single-molecule magnets (SMMs) ${ }^{1-7}$ and single-ion magnets (SIMs) ${ }^{8-}$ ${ }^{12}$, are zero dimensional molecular systems displaying magnetization blocking at low temperatures, quantum tunneling of magnetization (QTM) ${ }^{13}$ and quantum coherence. ${ }^{14,15}$ Accordingly, SMMs have attracted a great attention as promising candidates for quantum processing, ${ }^{16}$ high-density information storage, ${ }^{17}$ and molecular spintronic materials. ${ }^{18-21}$

Initial studies of SMMs were devoted to polynuclear coordination compounds of high nuclearity to get large ground spin states. ${ }^{2}$ Nevertheless, it is difficult to combine a large high ground spin state with a large magnetic anisotropy, and since the symmetry in a polynuclear complex often rises with growth of the nuclearity resulting in a low magnetic anisotropy. Last advanced SMMs studies focus on enhancing magnetic anisotropy, rather than enlarging ground spin states, which is a much more efficient way to rise the activation energy barrier and the blocking temperature. Consequently, studies into SMMs and SIMs, based on trivalent lanthanide ions $\left(\mathrm{Ln}^{\mathrm{III}}\right)$, develop at a high speed because of their significant magnetic anisotropy that comes from both spin-orbit coupling (SOC) and crystal-field splitting (CFS), where CFS is usually much smaller than SOC in $\mathrm{Ln}^{\mathrm{III}} .{ }^{22,5}$ It is very important to study small changes in ligand-field strength associated with the coordination geometries of $\mathrm{Ln}^{\mathrm{III}}$ complexes, but it is extremely hard to systematically control the coordination geometries and the ligand-field strength of $\mathrm{Ln}^{\mathrm{III}}$ compounds.

In addition, the internal $4 f$ electrons are strongly shielded by the outer shell electrons and thus obstruct a favorable magnetic exchange coupling, which can be used to enhance the magnetic advances. ${ }^{12}$ In this case, radical ligands may be considered as especially suitable for supporting strong interactions, and study the influence over the slow relaxation process of the magnetization. ${ }^{5}$ Numerous Ln-based complexes comprising diverse radical ligands, such as nitronyl nitroxides, ${ }^{23-26}$ oxidized phtalocyanine, ${ }^{26}$ semiquinolates,${ }^{27-29}$ verdazyls, ${ }^{30}$ triazinyl, ${ }^{31}$ bipyrimidyl, ${ }^{32}$ pyridylpyrazinyl, ${ }^{33}$ indigo anion, ${ }^{34}$ or dinitrogenyl ${ }^{35}$ have been reported. For instance, the later example has held the record for the highest coercivity of $14 \mathrm{~K}$ for many years. ${ }^{36}$

For mononuclear Ln-radical molecules, the magnetic relaxation is not only very sensitive to the symmetry of the ligand field around a central ion, but also related to magnetic interaction between $\mathrm{Ln}^{\mathrm{III}}$ ion and a radical. It is reported that in a highly symmetric crystal field, for example $\mathrm{C}_{\infty}, \mathrm{D}_{\infty h}, \mathrm{D}_{4 d}, \mathrm{D}_{5 h}$ and $\mathrm{D}_{6 d}$, the control of QTM becomes a reality. ${ }^{37-45}$
Since the dynamic magnetic behavior can be adjusted by careful fine-tuning of the ligand field around $\mathrm{Ln}^{\mathrm{III}}$, the choice of a radical ligand is especially important. Purposeful control of the structural parameters of complexes is impossible without ascertainment the influence of the geometry of the coordination polyhedron on the nature and magnitude of the parameters of the magnetic exchange interaction between a lanthanide ion and a radical center. In the last years, a series of Ln single radical complexes of the mono- ${ }^{46-48}$ bi- $^{49-56}$ and tri-coordinated ${ }^{57,58}$ nitroxides have been reported. Practically, all of them comprise three diamagnetic once negatively charged ligands - hexafluoroacetylacetonates $(h f a c)$.

It should be especially noted that the coordination chemistry of nitroxyl radicals and $d$-metals is much more developed compared to that of $4 f$ metals. Low donor ability of the nitroxyl group to $3 d$ metal ions can be recompensed by the use of auxiliary $h f a c$ ligands, which not only compensate for the charge of the metal ion, but also increase its accepting ability due to withdrawing effect of the trifluoromethyl groups. However, in the case of Ln-complexes, it is not necessary to use fluorinated acetylacetonates $(a c a c)$ to rise Lewis acidity of the neutral matrix $\left[\operatorname{Ln}(a c a c)_{3}\right]$, since the DFT calculations demonstrate that the charge on the central atom practically does not change when unsubstituted acac is replaced by fluorinated one. ${ }^{59,60}$

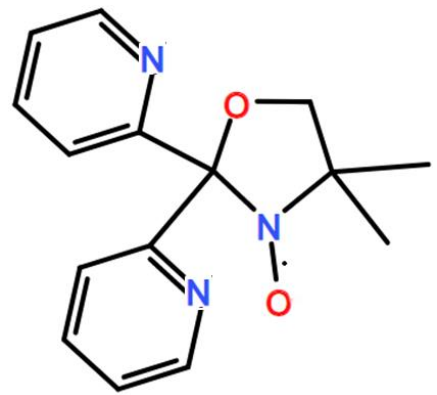

Scheme 1. Tridentate radical - 4,4-dimethyl-2,2-bis(pyridin-2-yl)1,3-oxazolidine-3-oxyl ( $\mathrm{Rad})$.

uxiliary ligands together with a radical ligand define the symmetry of the coordination environment of $\mathrm{Ln}$, and therefore CFS. The important point is that a large number of the mono- or bidentate ligands in coordination sphere of a metal does not contribute to the formation of the complex with desirable type of ligand field symmetry. Therefore, the use of the stereo- 
chemically rigid polydentate radicals with predictable coordination manner is promising. In this context, the 4,4-dimethyl-2,2-bis(pyridin-2-yl)1,3-oxazolidine-3-oxyl ( $\mathrm{Rad}$ ) acting as a tripodal ligand in complexes with $3 \mathrm{~d}$ metal ions is especially attracting.

In the present paper, we describe the synthesis of $\left[\operatorname{LnRad}\left(\mathrm{NO}_{3}\right)_{3}\right](\mathrm{Ln}$ $=\mathrm{Gd}, \mathrm{Tb}, \mathrm{Dy}, \mathrm{Tm}, \mathrm{Y})$ as the first example of lanthanide complexes with Rad (Scheme 1). Their structure and magnetic properties were carefully studied. To date, the coordination chemistry of Rad has been limited to complexes with $3 d$ metal ions (see, for example, papers ${ }^{61,62}$ and references therein).

\section{RESULTS AND DISCUSSION}

Synthesis. The paramagnetic ligand, Rad, comprises two donor nitrogen atoms and an oxygen atom of the NO-group and thus can occupy three sites in the coordination sphere of a central atom. In this context, Ln(III) nitrate salts turned out to be suitable precursors, because the three nitrate anions block six coordination sites leaving a space for one Rad ligand resulting in a neutral molecule. To avoid coordination of solvent molecules, we chose acetonitrile as a solvent. In addition to relatively low coordinating ability to lanthanides, acetonitrile is a polar solvent that provides a good solubility of the reagents and, thus, a high reaction rate. We performed the reactions of $\mathrm{Ln}\left(\mathrm{NO}_{3}\right)_{3}(\mathrm{Ln}=\mathrm{Gd}, \mathrm{Tb}, \mathrm{Dy}$, Tm and Y) with one equivalent of Rad to obtain molecular complexes [ $\left.\operatorname{LnRad}\left(\mathrm{NO}_{3}\right)_{3}\right]$. Yttrium congener was synthesized to check isostructurality in the series and was not studied in detail. The phase purity of the bulk samples was confirmed by elemental and XRD analyses as shown in Figure S1 (See Supporting information) ${ }^{\dagger}$.
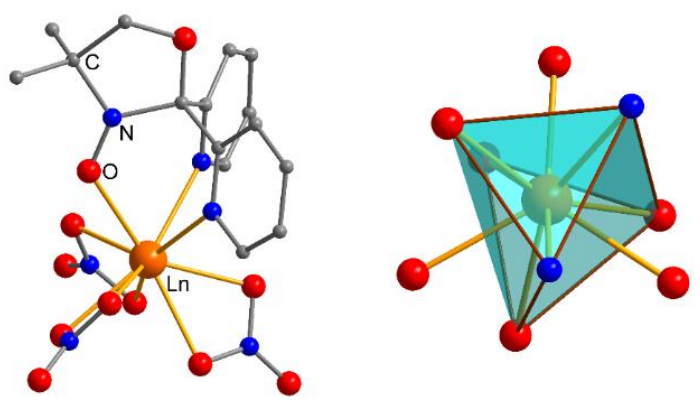

Figure 1. Molecule structure of $\left[\mathrm{LnRad}\left(\mathrm{NO}_{3}\right)_{3}\right]$ (left), hydrogen atoms are omitted; coordination polyhedron of $\mathrm{Ln}$ in $\left[\mathrm{LnRad}\left(\mathrm{NO}_{3}\right)_{3}\right]$ (right) described as a spherical tricapped trigonal prism (colored in blue).

Crystal Structures. Powder X-ray diffraction analysis revealed $\left[\operatorname{LnRad}\left(\mathrm{NO}_{3}\right)_{3}\right]$ compounds are isostructural. The crystal structures for the radical species for $\mathrm{Ln}=\mathrm{Dy}, \mathrm{Tm}$ and $\mathrm{Y}$ have been ascertained by Xray diffraction experiments on single crystals grown by a slow evaporation of the reaction mixture. In the complexes, Rad coordinates the lanthanide ion in a tridentate manner via two $\mathrm{N}$ atoms of the pyridine groups and $\mathrm{O}$ atom of NO moiety (Figure 1a). The coordination sphere is further complemented by three bidentate nitrates to give $\mathrm{LnO}_{7} \mathrm{~N}_{2}$ polyhedron. According to the Continuous Symmetry Measures (CSM) method, ${ }^{63}$ the polyhedron can be best described as a spherical tricapped trigonal prism (Figure $1 \mathrm{~b}$ ), although its symmetry noticeably deviates from $\mathrm{D}_{3 \mathrm{~h}}$ (Table $\mathrm{S} 1)^{\dagger}$. The donor atoms of Rad compose a triangular face of the prism. The Ln-O bond distances associated with the NO moiety are 2.37, 2.38 and $2.35 \AA$ for $\mathrm{Ln}=\mathrm{Y}$, Dy and Tm, respectively. $\mathrm{N}-\mathrm{O}$ bonds of the aminoxyl moiety varies in $1.27-1.28 \AA$ interval. Note, all bond lengths and angles of the complexes lie in the expected range. They are listed in Table S2 ${ }^{\dagger}$. The shortest intermolecular $\mathrm{Ln} \cdots \operatorname{Ln}$ distance is ca. 7.2 $\AA$. Through these distances, the molecules are combined into a chain spreading along the [101] crystal direction (Figure S2) ${ }^{\dagger}$. Between the chains, Ln $\cdots$ Ln distances of ca. 8.9 and $9.1 \AA$ are found.

Photophysical properties. Photophysical properties of the compounds were studied for $\mathrm{Tb}$ derivative as a representative of the luminous lanthanide in the visible region. Solutions of $\operatorname{Rad}$ and $\left[\operatorname{TbRad}\left(\mathrm{NO}_{3}\right)_{3}\right]$ in acetonitrile exhibit alike absorption spectra, indicating that energy levels of the radical are weakly affected by the lanthanide. ${ }^{64} \mathrm{~A}$ single absorption band peaks at ca. $260 \mathrm{~nm}$ having higher intensity for Rad compared to the complex. Free radical does not show luminescence both in the solid state and solution, while the complex shows a weak lanthanide centered emission typical for $\mathrm{Tb}^{\mathrm{III}}$ ions. The luminescence spectra of $\left[\mathrm{TbRad}\left(\mathrm{NO}_{3}\right)_{3}\right]$ in the solid state and the solution are similar, and the position of the bands is excitation wavelength independent.

Static magnetic properties. Magnetic measurements were performed on polycrystalline samples. Direct current $(d c)$ magnetic susceptibilities for the complexes were measured in the temperature range of 2-300 K under an applied magnetic field of 1 or $10 \mathrm{kOe}$ for the $\mathrm{Gd}$, $\mathrm{Tb}$, Dy and Tm species, respectively.

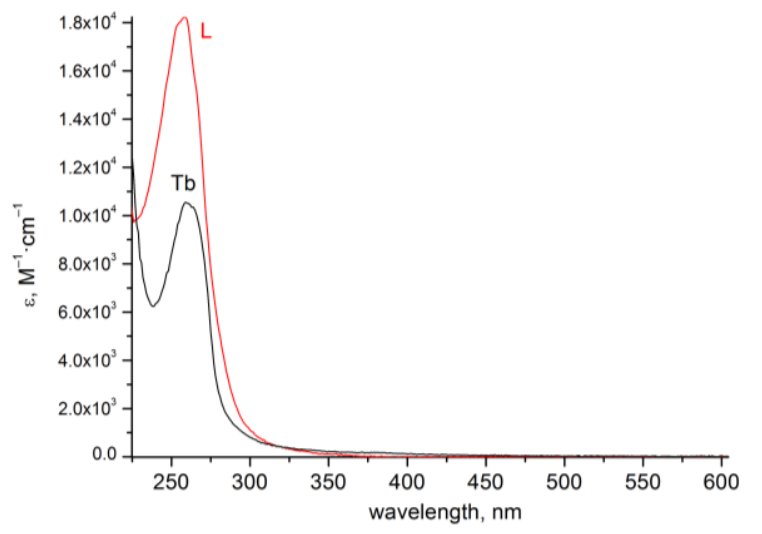

Figure 2. UV-Vis spectra of $\mathrm{Rad}(\mathrm{red})$ and $\left[\mathrm{TbRad}\left(\mathrm{NO}_{3}\right)_{3}\right]$ (black) in $\mathrm{CH}_{3} \mathrm{CN}$.

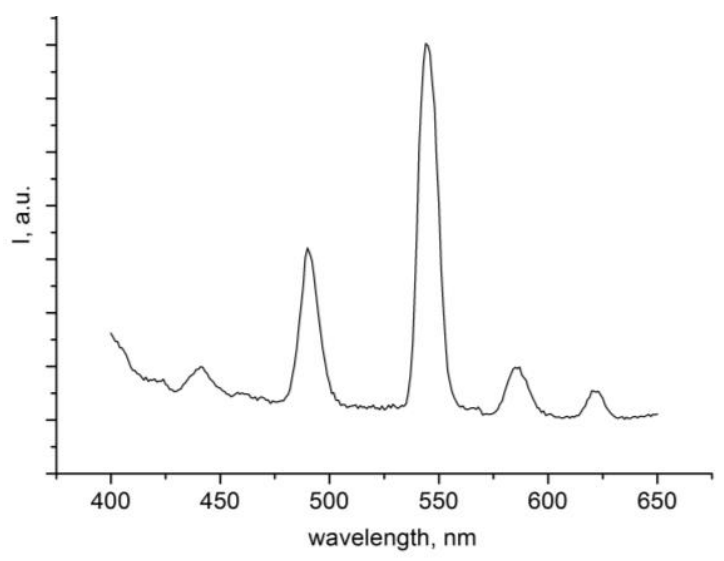

Figure 3. Photoluminescence spectrum of the solid compound $\left[\mathrm{TbRad}\left(\mathrm{NO}_{3}\right)_{3}\right], \lambda_{\text {exc }}=270 \mathrm{~nm}$.

The temperature dependence of the magnetic susceptibility $\chi T$ versus $T$ for all the investigated compounds is shown in Figure 4a. At $300 \mathrm{~K}$, the $\chi T$ values are $7.814,12.210,14.366,7.376, \mathrm{emu} \mathrm{K} \mathrm{mol}^{-1}$ for $\mathrm{Gd}, \mathrm{Tb}, \mathrm{Dy}$, and $\mathrm{Tm}$, respectively. These values are well consistent with the expected values for the appropriate $\mathrm{Ln}^{\mathrm{III}}$ ion plus a radical $(8.255,12.195,14.545$, $7.525 \mathrm{emu} \mathrm{K} \mathrm{mol}{ }^{-1}$ ). When the temperature is lowered, the value of $\chi T$ for all derivatives drops significantly. This can be attributed to CFS and/or the effect of the antiferromagnetic metal-radical coupling; in particular, we expect a dominance of the CFS for all Ln except Gd (isotropic at first order). Although it is often difficult to experimentally determine the ground state composition of anisotropic lanthanides in low symmetry environment, the Tm derivative of this series constitutes an exception, since it clearly stabilizes the nonmagnetic $m_{J}=0$ ground state $(\chi T$ drops to $0.375 \mathrm{emu} \mathrm{K} \mathrm{mol}{ }^{-1}$, the value of a free radical). Moreover, the significant drop in $\chi T$ for Gd suggests a high antiferromagnetic (AFM) coupling between the $\mathrm{Gd}^{\mathrm{III}}$ ion and the radical. In order to gain more insight on the magnetic behavior of these complexes, we recorded $M$ vs $B$ dependencies at $T=2 \mathrm{~K}$, reported in Figure $4 \mathrm{~b}$. The values for $\mathrm{Tb}$ and Dy complexes are close to those commonly reported in literature, but since the nature of the ground state of these ions can influence greatly these values, no decisive information about the coupling can be straightforwardly obtained. 
The value of $1.5 \mu_{\mathrm{B}}$ observed for Tm is consistent with a free radical (1 $\left.\mu_{\mathrm{B}}\right)$ and a largely diamagnetic ground state of the metal ion. Again, the curve for the Gd complex is the richest in information. Considering the low crystal field splitting typical of $\mathrm{Gd}$, the saturation value of $6 \mu_{\mathrm{B}}$ is consistent with an AFM coupling between a spin $S=7 / 2$ and a radical spin $S=1 / 2\left(S_{\text {tot }}=7 / 2-1 / 2=3\right)$.
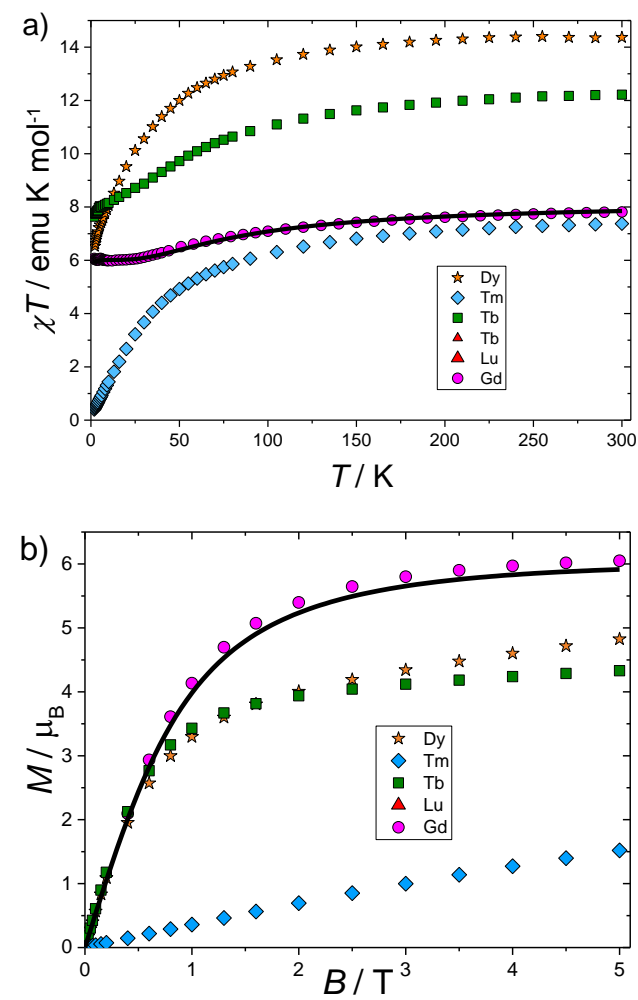

Figure 4. a) Temperature dependence of $\chi T$ and b) Magnetization curves of $\left[\mathrm{LnRad}\left(\mathrm{NO}_{3}\right)_{3}\right](\mathrm{Ln}=\mathrm{Gd}, \mathrm{Tb}$, Dy, and Tm). The black line represents the best simulation (see text).

Electron Paramagnetic Resonance. $\mathrm{X}$ band EPR has been performed on $\left[\mathrm{GdRad}\left(\mathrm{NO}_{3}\right)_{3}\right]$ in order to obtain precise information about the electronic structure. The spectrum of Gd exhibits several broad transitions.

A satisfactory fit of both the EPR and the static magnetic measurements can be obtained using the following Hamiltonian:

$$
\begin{gathered}
\mathcal{H}=b_{2}^{0} \hat{O}_{2}^{0}+b_{2}^{2} \hat{O}_{2}^{2}+b_{4}^{0} \hat{O}_{4}^{0}+j \hat{S}_{G d} \cdot \hat{S}_{\text {rad }}+g_{G d} \mu_{B} \hat{S}_{G d} \cdot B \\
+g_{\text {rad }} \mu_{B} \hat{S}_{\text {rad }} \cdot B
\end{gathered}
$$

Where the first three terms parametrize the CFS of the $\mathrm{Gd}^{\mathrm{III}}$ ion, the fourth term is the isotropic magnetic coupling between $\mathrm{Gd}$ and the radical and the last two terms are the Zeeman splitting for Gd and the radical, respectively.

The best simulation (black lines in Figure 4 and in Figure 5) was obtained with the following values: $b_{2}{ }^{0}=5.210^{-2} \mathrm{~cm}^{-1}, b_{2}{ }^{2}=1.110^{-2}$ $\mathrm{cm}^{-1}, b_{4}^{0}=3.810^{-4} \mathrm{~cm}^{-1}, j=+23 \mathrm{~cm}^{-1}, g_{\mathrm{Gd}}=2.0023$ and $g_{\mathrm{rad}}=1.998$. Importantly, the value of $+23 \mathrm{~cm}^{-1}$ of the coupling constant is remarkably large for gadolinium complexes of organic radicals. For example, for hexafluoroacetylacetonate gadolinium complexes containing one acyclic nitroxyl radical, ${ }^{65,66,47}$ the value of $|j|$ varies between 9.6 and $12.5 \mathrm{~cm}^{-1}$. For the analogous compounds comprising one nitronyl nitroxyl radical, ${ }^{50,51,57,52,49,67,53}$ exchange coupling is also lower $(|j|=$ $\left.0.77 \div 8.35 \mathrm{~cm}^{-1}\right)$. For the Gd-complex of the closest relative of $\mathrm{Rad}$ TEMPO (TEMPO = 2,2,6,6-tetramethylpiperidin-1-oxyl) metal-radical interaction is small $\left(j=2.43 \mathrm{~cm}^{-1}\right){ }^{68}$ For the mono-semiquinone complex $\left[\mathrm{Gd}\left(\mathrm{HBTp}_{3}\right)_{2} \mathrm{SQ}\right] j=11.4 \mathrm{~cm}^{-1} .{ }^{69}$ Moreover, the strength of the exchange interaction $\mathrm{Gd}$-radical for the $\left[\mathrm{GdRad}\left(\mathrm{NO}_{3}\right)_{3}\right]$ specie is a half of that found for the binuclear Gd complex of the purely inorganic single radical $\mathrm{N}_{2}{ }^{3-}$ obtained in the group of Long. ${ }^{35}$

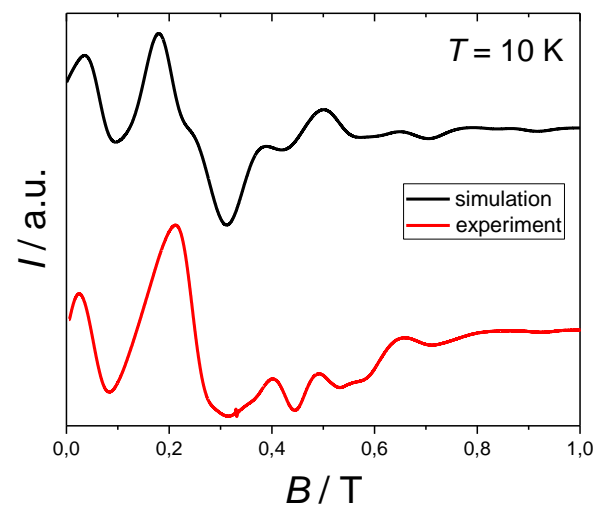

Figure 5. $\mathrm{X}$ band EPR of $\left[\mathrm{GdRad}\left(\mathrm{NO}_{3}\right)_{3}\right]$. For the best-fit parameters, see text.

Dynamic magnetic properties. $A C$ magnetic measurements were performed to gain information on the magnetization dynamics at low temperatures. For all the complexes we initially performed a frequency scan at various applied fields at the lowest reachable temperature $(T=$ $2 \mathrm{~K}$ ). The only compound to display a relevant nonzero out of phase magnetic susceptibilities was $\left[\operatorname{TbRad}\left(\mathrm{NO}_{3}\right)_{3}\right]$ (see Figures S3 and S4) ${ }^{\dagger}$. This complex shows slow relaxation both with and without an external applied field. In zero applied field the relaxation of $\mathrm{Tb}$ derivative at the lowest temperature is at the upper edge of the measurable frequency (relaxation time ca. $16 \mu \mathrm{s}$ ), thus a temperature study was impossible.

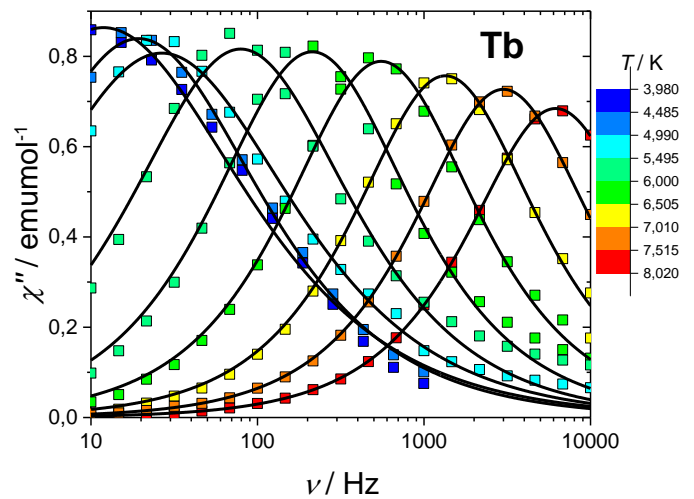

Figure 6. Thermal evolution of the imaginary component of the $a c$ magnetic susceptibility for $\left[\mathrm{TbRad}\left(\mathrm{NO}_{3}\right)_{3}\right]$ in an applied field of 0.1

T. The black lines represent the best fit.

Upon application of an external magnetic field, the slow relaxation of $\left[\operatorname{TbRad}\left(\mathrm{NO}_{3}\right)_{3}\right]$ slows down by several orders of magnitude. The temperature evolution of the imaginary component of the magnetic susceptibility with an optimum field of $0.1 \mathrm{~T}$ is shown in Figure 6 . The real components are presented in Figure $\mathrm{S} 4{ }^{\dagger}$.

The curves were fitted using a generalized Debye model. ${ }^{70}$ The $\alpha$ value (Figure S5) ${ }^{\dagger}$ is in the typical range for SMMs $(0.01<\alpha<0.3)$, assuring a relatively narrow distribution of relaxation times. The $\chi_{\mathrm{T}-} \chi_{\mathrm{S}}$ values are reported in Figure $\mathrm{S}^{\dagger}$ and compared with the susceptibility measured in $D C$ mode. Since the static magnetic field was the same in the two measurements $(B=0.1 \mathrm{~T})$, the comparison is straightforward. The two values are coincident thus, all the magnetically active centers in the sample are slowly relaxing with the channel monitored in the $A C$ experiments.

The best fit was achieved using a sum of quantum tunnelling and Orbach processes ${ }^{71}$

$$
\tau^{-1}=\tau_{Q T}^{-1}+\tau_{0}^{-1} e^{-\Delta E / k_{B} T}
$$

With $\tau_{Q T}=12(1) \mathrm{ms}, \tau_{0}=0.9(3) \mathrm{ns}$ and $\Delta \mathrm{E}=57 \mathrm{~cm}^{-1}$. It is important to remark here that only a detailed spectroscopic investigation, beyond the scope of this paper, could verify the validity of the extracted effective barrier. 


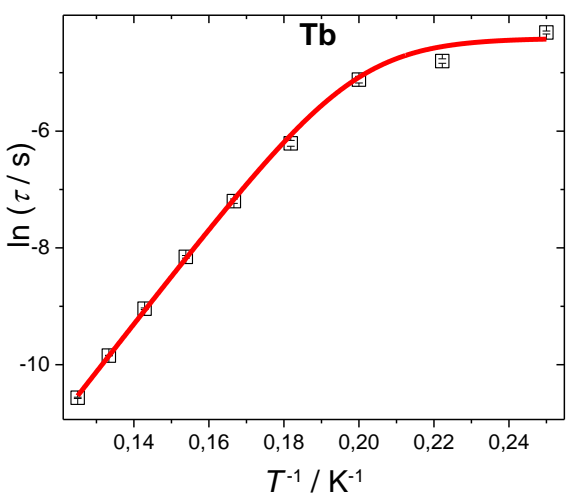

Figure 7. Relaxation times (symbols) extracted for $\left[\operatorname{TbRad}\left(\mathrm{NO}_{3}\right)_{3}\right]$ from the $a c$ measurements and best fit (red line).

\section{CONCLUSIONS}

A row of isostructural compounds was obtained by exploiting the coordination ability of the paramagnetic ligand 4,4-dimethyl-2,2-bis(pyridin-2-yl)-1,3-oxazolidine with lanthanide nitrates. XRD on single crystals and powders studies showed that the neutral archetype molecule of the family of complexes $\left(\left[\mathrm{LnRad}\left(\mathrm{NO}_{3}\right)_{3}\right], \mathrm{Ln}=\mathrm{Gd}, \mathrm{Tb}, \mathrm{Dy}, \mathrm{Tm}\right.$, $\mathrm{Y})$ has a symmetry close to $D_{3 \mathrm{~h}}$ and consists of one radical attached to the central atom in a tripodal manner and three nitrate anions, each of which is coordinated by two oxygen atoms.

The $\chi T$ values at ambient temperature confirm the presence of one paramagnetic ligand in the complexes. The $D C$ magnetic studies demonstrate the presence of an antiferromagnetic Gd-radical exchange interaction. The best simulation of both the EPR and the static magnetic measurements for $\left[\mathrm{GdRad}\left(\mathrm{NO}_{3}\right)_{3}\right]$ was obtained with $g_{G d}=2.0023, g_{\text {rad }}=1.998$ and coupling constant $j=23 \mathrm{~cm}^{-1}$, which is a record strength ever found for the complexes of $4 \mathrm{f}$-elements with nitroxyl radicals. The terbium derivative displays frequency-dependent out-of-phase signals in zero field, indicating single-molecule magnetic behavior with an effective barrier of $57 \mathrm{~cm}^{-1}$. The next stage of our research will be aimed at the synthesis and investigation of complexes of lanthanides with two radicals.

\section{EXPERIMENTAL SECTION}

The chemicals were obtained from commercial sources and used as received. The 4,4-dimethyl-2,2-bis(pyridin-2-yl)-1,3-oxazolidine Noxyl radical was synthesized according to known procedure. ${ }^{72}$ $\mathrm{Y}\left(\mathrm{NO}_{3}\right)_{3} \cdot 6 \mathrm{H}_{2} \mathrm{O}$ and $\mathrm{Tb}\left(\mathrm{NO}_{3}\right)_{3} \cdot 6 \mathrm{H}_{2} \mathrm{O}$ were used as received from suppliers. $\mathrm{Ln}\left(\mathrm{NO}_{3}\right)_{3} \cdot \mathrm{xH}_{2} \mathrm{O}(\mathrm{Ln}=\mathrm{Gd}, \mathrm{Dy}, \mathrm{Tm})$ were prepared upon dissolution of the corresponding $\mathrm{Ln}_{2} \mathrm{O}_{3}$ in diluted $\mathrm{HNO}_{3}$ at $50^{\circ} \mathrm{C}$ followed by evaporation of all volatiles. The prepared salts were quantitatively transferred to further reactions to ensure proper loading of the lanthanides. Elemental analysis was performed with a Eurovector EuroEA3000 analyzer. IR spectra were recorded in $\mathrm{KBr}$ pellets by means of FT-801 Fourier spectrometer (Simex). Powder XRD was carried out using a Shimadzu XRD-7000 diffractometer (CuK $\alpha$ radiation, Ni filter, $2 \theta$ angle range from $5^{\circ}$ to $30^{\circ}$ ) using Dectris MYTHEN2 R $1 \mathrm{~K}$ detector. UV-Vis spectra were measured with a Cary60 UV-Vis (Agilent) spectrophotometer in acetonitrile solutions using $10 \mathrm{~mm}$ quartz cuvettes, concentration of ca. $10^{-5} \mathrm{M}$. The photoluminescence and excitation spectra were recorded for the same solutions on a Cary Eclipse Fluorescence Spectrophotometer (Agilent).

Synthesis of the compounds. $\left[\operatorname{LnRad}\left(\mathrm{NO}_{3}\right)_{3}\right](\mathrm{Ln}=\mathrm{Y}, \mathrm{Gd}, \mathrm{Tb}, \mathrm{Dy}$, $\mathrm{Tm})$ were prepared according to the procedure described for Dy congener. To a solution of $\mathrm{Dy}\left(\mathrm{NO}_{3}\right)_{3} \cdot \mathrm{xH}_{2} \mathrm{O}(0.113 \mathrm{mmol})$ in $\mathrm{CH}_{3} \mathrm{CN}(2 \mathrm{~mL})$, solution of $\operatorname{Rad}(0.107 \mathrm{mmol})$ in $\mathrm{CH}_{3} \mathrm{CN}(1.5 \mathrm{~mL})$ was added. Pale yellow solution was stirred for $1 \mathrm{~h}$ followed by slow evaporation of the solvent. Pale yellow crystalline or fine powder product was washed with acetone and dried in vacuo. Yield: $80 \%$. Anal. calcd (\%) for $\mathrm{C}_{15} \mathrm{H}_{16} \mathrm{DyN}_{6} \mathrm{O}_{11}$ : C, 29.1; H, 2.6; N, 13.6. Found: C, 28.1; H, 2.5; N, 13.3. IR (KBr): v (cm $\left.{ }^{-1}\right) 3383$ (br), 3132 (w), 2987 (w), 2897 (w), 1604 (s), 1536 (sh), 1521 (s), 1507 (s), 1491 (s), 1476 (s), 1440 (s), 1384 (s), 1294 (s), 1272 (s), 1194 (w), 1163 (m), 1077 (m), 1063 (m), 1024 (s), $1005(\mathrm{~m}), 982(\mathrm{w}), 813(\mathrm{~m}), 772(\mathrm{~s}), 748(\mathrm{~m}), 708(\mathrm{w}), 664(\mathrm{~m}), 643$ (m), $638(\mathrm{~m}), 620(\mathrm{w}), 569(\mathrm{w})$. For all complexes, the IR spectra are essentially similar: the position of the bands differs less than $2 \mathrm{~cm}^{-1}$.

[YRad(NO3 $\left.)_{3}\right] . \mathrm{Y}\left(\mathrm{NO}_{3}\right)_{3} \cdot 6 \mathrm{H}_{2} \mathrm{O}-0.154 \mathrm{mmol}, \mathrm{L}-0.152 \mathrm{mmol}$. Yield of $30 \%$ is low due to the tendency of the product to form an oil. $\mathrm{C}_{15} \mathrm{H}_{16} \mathrm{~N}_{6} \mathrm{O}_{11} \mathrm{Y}$ (545.2) calcd. C, 33.0; H, 3.0; N, 15.4. Found: C, 33.1; $\mathrm{H}, 2.9 ; \mathrm{N}, 15.2$.

[GdRad(NO $\left.)_{3}\right)_{3}$. $\mathrm{Gd}\left(\mathrm{NO}_{3}\right)_{3} \cdot \mathrm{xH}_{2} \mathrm{O}-0.167 \mathrm{mmol}, \mathrm{Rad}-0.167 \mathrm{mmol}$. Yield 55\%. $\mathrm{C}_{15} \mathrm{H}_{16} \mathrm{~N}_{6} \mathrm{O}_{11} \mathrm{Gd}$ (613.6) calcd C, 29.31; H, 2.62; N, 13.68. Found: C, 29.4; H, 2.6; N, 13.7.

[TbRad(NO3) $\left.)_{3}\right] . \mathrm{Tb}\left(\mathrm{NO}_{3}\right)_{3} \cdot 6 \mathrm{H}_{2} \mathrm{O}-0.592 \mathrm{mmol}, \mathrm{Rad}-0.598 \mathrm{mmol}$.

Yield $40 \%$. $\mathrm{C}_{15} \mathrm{H}_{16} \mathrm{~N}_{6} \mathrm{O}_{11} \mathrm{~Tb}(615.2)$ calcd. C, 29.28; H, 2.62; N, 13.66. Found: C, 29.3; H, 2.7; N, 13.9.

[TmRad(NO $\left.\mathbf{N}_{3}\right)_{3}$ ]. Tm(NO$\left(\mathrm{NO}_{3}\right)_{3} \cdot \mathrm{xH}_{2} \mathrm{O}-0.166 \mathrm{mmol}, \mathrm{Rad}-0.150 \mathrm{mmol}$. Yield 50\%. $\mathrm{C}_{15} \mathrm{H}_{16} \mathrm{~N}_{6} \mathrm{O}_{11} \mathrm{Tm}$ (625.2) calcd. C, 28.8; H, 2.6; N, 13.4. Found: C, 28.6; H, 2.4; N, 13.2.

$\mathrm{X}$-ray structure determination. Single-crystal XRD data for the compounds were collected a Bruker Apex X8 diffractometer equipped with a $4 \mathrm{~K} \mathrm{CCD}$ area detector using the graphite-monochromated Mo K $\alpha$ radiation $(\lambda=0.71073 \AA)$ (Table S3) at 298K. The $\varphi$ - and $\omega$-scan techniques were employed to measure intensities. Absorption corrections were applied with the use of the SADABS program. ${ }^{73}$ The crystal structures were solved using the SHELXT ${ }^{74}$ and were refined using SHELXL ${ }^{75}$ programs with OLEX 2 GUI $^{76}$. Atomic displacement parameters for non-hydrogen atoms were refined anisotropically. CCDC 1570960-1570962 contain the supplementary crystallographic data for this paper. These data can be obtained free of charge via www.ccdc.cam.ac.uk/data_request/cif, or by emailing data_request@ccdc.cam.ac.uk, or by contacting The Cambridge Crystallographic Data Centre, 12 Union Road, Cambridge CB2 1EZ, UK; fax: +44 1223336033 .

Magnetic measurements. DC and AC magnetic properties of the compounds were determined by measuring polycrystalline samples pressed in Teflon pellet to avoid preferential orientation of the crystallites, using a QD MPMS SQUID magnetometer in the temperature range 1.9-300 $\mathrm{K}$ with applied field up to $5.5 \mathrm{~T}$ in the frequency range $1-10000 \mathrm{~Hz}$ (for ac characterization). The intrinsic diamagnetic contributions of the samples have been estimated using Pascal's constants Diamagnetic Corrections and Pascal's Constants. ${ }^{77}$

\section{ACKNOWLEDGMENT}

This work is supported by RFBR according to the research project № 20-33-70172. MP and AC thank "Centro per servizi di cristallografia strutturale dell'Università degli Studi di Firenze" for powder XRD experiments.

\section{REFERENCES}

1. Sessoli, R.; Gatteschi, D.; Caneschi, A.; Novak, M. A. Magnetic bistability in a metal-ion cluster. Nature 1993, 365, 141-143. 10.1038/365141a0

2. Christou, G.; Gatteschi, D.; Hendrickson, D. N.; Sessoli, R. Single-molecule magnets. MRS Bull. 2000, 25, 66-71. $10.1557 / \mathrm{mrs} 2000.226$

3. Gatteschi, D.; Sessoli, R.; Villain, J. Molecular Nanomagnets; Oxford University Press: Oxford, UK, 2006.

4. Jeon, I.-R.; Clerac, R. Controlled association of single-molecule magnets (SMMs) into coordination networks: towards a new generation of magnetic materials.Dalton. Trans. 2012, 41 (32), 9569-9586. 10.1039/C2DT30906H

5. Demir, S.; Jeon, I.-R.; Long, J. R.; Harris, T. D. Radical ligandcontaining single-molecule magnets. Coord. Chem. Rev. 2015, 289 290, 149-176. 10.1016/j.ccr.2014.10.012

6. Sessoli, R.; Powell, A. K. Strategies towards single molecule magnets based on lanthanide ions. Coord. Chem. Rev. 2009, 253, 23282341. 10.1016/j.ccr.2008.12.014

7. Woodruff, D. N.; Winpenny, R. E. P.; Layfield, R.A. Lanthanide single-molecule magnets. Chem. Rev. 2013,113 (7), 5110-5148. $10.1021 / \mathrm{cr} 400018 \mathrm{q}$

8. Craig, G. A.; Murrie, M. 3d Single-ion magnets. Chem. Soc. Rev. 2015, 44 (8), 2135-2147. 10.1039/C4CS00439F 
9. Frost, J. M.; Harriman, K. L. M.; Murugesu, M. The rise of 3-d single-ion magnets in molecular magnetism: towards materials from molecules? Chem. Sci. 2016, 7 (4), 2470-2491. 10.1039/C5SC03224E 10. Bar, A. K.; Pichon, C.; Sutter, J.-P. Magnetic anisotropy in twoto eight-coordinated transition-metal complexes: Recent developments in molecular magnetism. Coord. Chem. Rev. 2016, 308, 346-380. 10.1016/j.ccr.2015.06.013

11. Meng, Y. S.; Jiang, S. D.; Wang, B. W.; Gao, S. Understanding the magnetic anisotropy toward single-ion magnets. Acc. Chem. Res. 2016, 49 (11), 2381-2389. 10.1021/acs.accounts.6b00222

12. McAdams, S. G.; Ariciu, A.-M.; Kostopoulos, A. K.; Walsh, J. P. S.; Tuna, F. Molecular single-ion magnets based on lanthanides and actinides: Design considerations and new advances in the context of quantum technologies. Coord. Chem. Rev. 2017, 346, 216-239. 10.1016/j.ccr.2017.03.015

13. Gatteschi, D.; Sessoli, R. Quantum Tunneling of Magnetization and Related Phenomena in Molecular Materials. Angew. Chem. Int. Ed. 2003, 42 (3), 268-297. 10.1002/anie.200390099

14. Schlegel, C.; van Slageren, J.; Manoli, M.; Brechin, E. K.; Dressel, M. Direct observation of quantum coherence in single-molecule magnets. Phys. Rev. Lett. 2008, 101 (14), 147203. 10.1103/PhysRevLett.101.147203

15. Bader, K.; Dengler, D.; Lenz, S.; Endeward, B.; Jiang, S.-D.; Neugebauer, P.; van Slageren, J. Room temperature quantum coherence in a potential molecular qubit. Nat. Commun. 2014, 5 (1), 5304. 10.1038 /ncomms6304

16. Leuenberger, M.N.; Loss, D. Quantum computing in molecular magnets. Nature 2001, 410 (6830), 789-793. 10.1038/35071024

17. Mannini, M.; Pineider, F.; Sainctavit, P.; Danieli, C.; Otero, E.; Sciancalepore, C.; Talarico, A. M.; Arrio, M.-A.; Cornia, A.; Gatteschi, D.; Sessoli, R. Magnetic memory of a single-molecule quantum magnet wired to a gold surface. Nat. Mater. 2009, 8 (3), 194-197. $10.1038 /$ nmat 2374

18. Bogani, L.; Wernsdorfer, W. Molecular spintronics using single-molecule magnets. Nat. Mater. 2008, 7 (3), 179. 10.1038/nmat2133 19. Camarero, J.; Coronado, E. Molecular vs. inorganic spintronics: the role of molecular materials and single molecules. J. Mater. Chem. 2009, 19(12), 1678-1684. 10.1039/b819594n

20. Sanvito, S. Molecular spintronics. Chem. Soc. Rev. 2011, 40 (6), 3336-3355. 10.1039/C1CS15047B

21. Sorace, L.; Benelli, C.; Gatteschi, D. Lanthanides in molecular magnetism: old tools in a new field. Chem. Soc. Rev. 2011, 40 (6), 3092-3104. 10.1039/c0cs00185f

22. Liddle, S.T.; van Slageren, J. Improving f-element single molecule magnets. Chem. Soc. Rev. 2015, 44 (19), 6655-6669. 10.1039/C5CS00222B

23. Kahn, M. L.; Sutter, J.-P.; Golhen, S.; Guionneau, P.; Ouahab, L.; Kahn O.; Chasseau, D. Systematic Investigation of the Nature of The Coupling between a $\mathrm{Ln}(\mathrm{III})$ Ion $(\mathrm{Ln}=\mathrm{Ce}(\mathrm{III})$ to $\mathrm{Dy}(\mathrm{III}))$ and Its Aminoxyl Radical Ligands. Structural and Magnetic Characteristics of a Series of $\left\{\operatorname{Ln}(\text { organic radical })_{2}\right\}$ Compounds and the Related $\left.\{\text { Ln(Nitrone) })_{2}\right\}$ Derivatives J. Am. Chem. Soc. 2000, 122 (14), 34133421. 10.1021/ja994175o

24. Bogani, L.; Sangregorio, C.; Sessoli, R.; Gatteschi, D. Molecular engineering for single-chain-magnet behavior in a one-dimensional dysprosium-nitronyl nitroxide compound. Angew. Chem. Int. Edit. 2005, 44 (36), 5817-5821. 10.1002/anie.200500464

25. Bernot, K.; Bogani, L.; Caneschi, A.; Gatteschi, D.; Sessoli, R. A Family of Rare-Earth-Based Single Chain Magnets: Playing with Anisotropy. J. Am. Chem. Soc. 2006, 128 (24), 7947-7956. $10.1021 / \mathrm{ja} 0611011$

26. Ishikawa, N.; Sugita, M.; Tanaka, N.; Ishikawa, T.; Koshihara, S.-Y.; Kaizu, Y. Inorg. Chem. 2004, 43 (18), 5498-5500. 10.1021/ic049348b

27. Dei, A.; Gatteschi, D.; Pecaut, J.; Poussereau, S.; Sorace L.; Vostrikova, K. Crystal field and exchange effects in rare earth semiquinone complexes C. R. Acad. Sci. Ser. IIC 2001, 4, 135. 10.1016/S13871609(00)01196-8

28. P. Zhang, M. Perfetti, M. Kern, P. P. Hallmen, L. Ungur, S. Lenz, M. R. Ringenberg, W. Frey, H. Stoll, G. Rauhut, J. van Slageren,
Exchange coupling and single molecule magnetism in redox-active tetraoxolene-bridged dilanthanide complexes Chem. Sci. 2018, 9 (5), 1221-1230. 10.1039/C7SC04873D

29. 2019Reed, W.; Dunstan, M.; Gable, R. W.; Phonsri, W.; Murray, K. S.; Mole, R.; Boskovic, C. Tetraoxolene-bridged rare-earth complexes: a radical-bridged dinuclear Dy single-molecule magnet. Dalton trans. 2019, 48 (41), 15635-15645. 10.1039/C9DT01320B

30. Norel, L.; Chamoreau, L.-M.; Journaux, Y.; Oms, O.; Chastanet, G.; Train, C. Chem. Commun. 2009, (17), 2381-2383. 10.1039/B816910A

31. Morgan, I. S.; Mansikkamaki, A.; Rouzieres, M.; Clerac, R.; Tuononen, H. M. Coexistence of long-range antiferromagnetic order and slow relaxation of the magnetization in the first lanthanide complex of a 1,2,4-benzotriazinyl radical. Dalton Trans. 2017, 46 (38), 1279012793. 10.1039/C7DT02766D

32. Demir, S.; Zadrozny, J. M.; Nippe, M.; Long, J. R. Exchange Coupling and Magnetic Blocking in Bipyrimidyl Radical-Bridged Dilanthanide Complexes. J. Am. Chem. Soc. 2012, 134 (45), 1854618549. 10.1021/ja308945d

33. Demir, S.; Nippe, M.; Gonzalez, M. I.; Long, J. R. Exchange coupling and magnetic blocking in dilanthanide complexes bridged by the multi-electron redox-active ligand 2,3,5,6-tetra(2-pyridyl)pyrazine. Chem. Sci. 2014, 5 (12), 4701-4711. 10.1039/c4sc02154aS

34. Guo F.-S.; Layfield, R. A. Strong direct exchange coupling and single-molecule magnetism in indigo-bridged lanthanide dimers. Chem. Commun. 2017, 53 (21), 3130-3133. 10.1039/C7CC01046J

35. Rinehart, J. D.; Fang, M.; Evans, W. J.; Long, J. R. Strong Exchange and Magnetic Blocking in $\mathrm{N}_{2}{ }^{3-}$ Radical-Bridged Lanthanide Complexes Nat. Chem. 2011, 3 (7), 538-542. 10.1038/nchem.1063

36. Rinehart, J. D.; Fang, M.; Evans, W. J.; Long, J. R. A N $2^{3-}$ Radical-Bridged Terbium Complex Exhibiting Magnetic Hysteresis at 14 K. J. Am. Chem. Soc. 2011, 133, 14236-14239. 10.1021/ja206286h

37. Görller-Walrand, C.; Binnemans, K.; Gschneidner, K. A.; Eyring, L. Handbook on the Physics and Chemistry of Rare Earths. 1996, vol. 23, Elsevier B.V., ISBN: 978-0-444-82507-0

38. Sørensen, M. A.; Hansen, U. B.; Perfetti, M.; Pedersen, K. S.; Bartolomé, E.; Simeoni, G. G.; Mutka, H.; Rols, S.; Jeong, M.; Zivkovic, I.; Retuerto, M.; Arauzo, A.; Bartolomé, J.; Piligkos, S.; Weihe, H.; Doerrer, L. H.; van Slageren, J.; Rønnow, H. M.; Lefmann, K.; Bendix J. Chemical tunnel-splitting-engineering in a dysprosiumbased molecular nanomagnet. Chemical tunnel-splitting-engineering in a dysprosium-based molecular nanomagnet. Nat. Comm. 2018, 9 (1), 1292. 10.1038/s41467-018-03706-x

39. Ishikawa, N.; Sugita, M.; Ishikawa, T.; Koshihara, S; Kaizu, Y. Lanthanide double-decker complexes functioning as magnets at the single-molecular level. J. Am. Chem. Soc. 2003, 125 (29), 8694-8695. 10.1021/ja029629n

40. AlDamen, M. A.; Clemente-Juan, J. M.; Coronado, E.; MartíGastaldo, C; Luis, F.; Gaita-Ariño, A. Mononuclear Lanthanide Single Molecule Magnets Based on the Polyoxometalates $\left[\mathrm{Ln}\left(\mathrm{W}_{5} \mathrm{O}^{1} 8\right)_{2}\right]^{9-}$ and $\left[\mathrm{Ln}\left(\beta_{2}-\mathrm{SiW}_{11} \mathrm{O}_{39}\right)_{2}\right]^{13-}\left(\mathrm{Ln}^{\mathrm{III}}=\mathrm{Tb}, \mathrm{Dy}, \mathrm{Ho}, \mathrm{Er}, \mathrm{Tm}\right.$, and $\left.\mathrm{Yb}\right) . J . A m$. Chem. Soc. 2009, 48 (8), 3467-3479. 10.1021/ic801630z.

41. Tanaka, D; Inose, T.; Tanaka, H.; Lee, S.; Ishikawa, N.; Ogawa, T. Proton-induced switching of the single molecule magnetic properties of a porphyrin based Tb III double-decker complex. Chem. Commun. 2012, 48(63), 7796-7798. 10.1039/C2CC00086E

42. Chen, Y.-C.; Liu, J.-L.; Ungur, L.; Liu, J.; Li, Q.-W.; Wang, L.F.; Ni, Z.-P.; Chibotaru, L. F.; Chen, X.-M.; Tong, M.-L. Symmetrysupported magnetic blocking at $20 \mathrm{~K}$ in pentagonal bipyramidal Dy(III) single-ion magnets. J. Am. Chem. Soc. 2016, 138 (8), 2829-2837. $10.1021 /$ jacs.5b13584

43. Liu, J.; Chen, Y.-C.; Liu, J.-L.; Vieru, V.; Ungur, L.; Jia, J.-H.; Chibotaru, L. F.; Lan, Y.; Wernsdorfer, W.; Gao, S.; Chen, X.-M.; Tong, M.-L. A Stable pentagonal bipyramidal Dy(III) single-ion magnet with a record magnetization reversal barrier over $1000 \mathrm{~K} . \mathrm{J}$. Am. Chem. Soc. 2016, 138 (16), 5441-5450. 10.1021/jacs.6b02638

44. Ding, Y.-S.; Chilton, N. F.; Winpenny, R. E. P.; Zheng, Y.-Z. On approaching the limit of molecular magnetic anisotropy: a near-perfect pentagonal bipyramidal dysprosium(III) single-molecule magnet. 
Angew. Chem. Int. Ed. 2016, 55 (52), 16071-16074. 10.1002/anie. 201609685

45. Bonde, N. A.; Petersen, J. B.; Sørensen, M. A.; Nielsen, U. G.; Fåk, B.; Rols, S.; Ollivier, J.; Weihe, H.; Bendix, J.; Perfetti, M. Importance of Axial Symmetry in Elucidating Lanthanide-Transition Metal Interactions. Inorg. Chem. 2020, 59 (1), 235-243. 10.1021/acs.inorgchem.9b02064

46. Kanetomo, T.; Ishida, T. Preparation and characterization of $\left[\mathrm{Gd}(\mathrm{hfac})_{3}(\mathrm{DTBN})\left(\mathrm{H}_{2} \mathrm{O}\right)\right](\mathrm{DTBN}=$ di-t-butyl nitroxide). Ferromagnetic $\mathrm{Gd}^{3+}-\mathrm{Gd}^{3+}$ super-superexchange. Chem. Commun. 2014, 50 (19), 2529-2531. 10.1039/C3CC48326F

47. Kanetomo, T.; Yoshitake, T.; Ishida, T. Strongest Ferromagnetic Coupling in Designed Gadolinium(III)-Nitroxide Coordination Compounds Inor. Chem. 2016, 55, 8140-8146, 10.1021/acs.inorgchem.6b01072

48. Benelli, C.; Caneschi, A.; Fabretti, A. C.; Gatteschi, D.; Pardi, L. Inorg. Chem.1990, 29 (20), 4153-4155, 10.1021/ic00345a050

49. Benelli, C.; Caneschi, A.; Gatteschi, D.; Pardi, L. Gadolinium(III) complexes with pyridine-substituted nitronyl nitroxide radicals. Inorg. Chem. 1992, 31, 31(5), 741-746. 10.1021/ic00031a010

50. Tian, L.; Chen, P.; Zhang, Y.-Q.; Wu, M. Z.; Liu, Z. Y. Dalton Trans. Slow relaxation of the magnetization observed in mononuclear Ln-radical compounds with $D_{4 \mathrm{~d}}$ geometry configurations. Dalton Trans., 2019, 48 (2), 558-565. 10.1039/C8DT03809K

51. Hu, P.; Zhu, M.; Mei, X.; Tian, H.; Ma, Y.; Li, L.; Liao, D. Single-molecule magnets based on rare earth complexes with chelating benzimidazole-substituted nitronyl nitroxide radicals. Dalton Trans., 2012, 41 (48), 14651-14656. 10.1039/c2dt31806g

52. Wang, J.; Miao, H.; Xiao, Z.-X.; Zhou, Y.; Deng, L.-D.; Zhang, Y.-Q.; Wang, X.-Y. Syntheses, structures and magnetic properties of the lanthanide complexes of the pyrimidyl-substituted nitronyl nitroxide radical. Dalton Trans. 2017, 46, 10452, 10.1039/C7DT01037K

53. Chen, P. Y.; Wu, M. Z.; Shi, X. J.; Tian, L. A family of multispin rare-earth complexes based on a triazole nitronyl nitroxide radical: synthesis, structure and magnetic properties. RSC Advances, 2018, 8 (28), 15480-15486. 10.1039/c8ra02546k

54. Wang, X.-L.; Li, L.-C.; Liao, D.-Z. Slow Magnetic Relaxation in Lanthanide Complexes with Chelating Nitronyl Nitroxide Radical. Inorg. Chem. 2010, 49 (11), 4735-4737. 10.1021/ic100008g

55. Zhu, L.-L.; Hu, P.; Cao, J.-F.; Zhao, Y.-H.; Wu, Y.-N.; Zhu, Y.$\mathrm{X}$;; Su, Y; Wang, C. Magnetic relaxation in mononuclear Tb and Dy complexes involving chelate nitronyl nitroxide ligand. Polyhedron 2018, 155, 375-381. 10.1016/j.poly.2018.08.058

56. Hu, P.; Guo, H.-F.; Li, Y.; Xiao F.-P. Three lanthanide-nitronyl nitroxide complexes: Syntheses, crystal structures and magnetic properties. Inorg. Chem. Commun. 2015, 59, 91-94. 10.1016/j.inoche.2015.07.003

57. Wang, X.; Zhu, M.; Wang, J.; Li, L. Unusual Gd-nitronyl nitroxide antiferromagnetic coupling and slow magnetic relaxation in the corresponding Tb analogue Dalton Trans. 2015, 44 (31), 13890-13896. 10.1039/C5DT01487E

58. Miao, H.; Li, H.-Q.; Shen, F.-X.; Wei, H.-Y.; Wang, B.-L.; Wang, X.-Y. A family of lanthanide complexes with a bis-tridentate nitronyl nitroxide radical: syntheses, structures and magnetic properties. Dalton Trans. 2019, 48 (27), 10337-10345. 10.1039/C9DT01397K

59. Rogachev, A. Y.; Mironov, A. V.; Troyanov, S. I.; Kuzmina, N. P.; Nemukhin, A. V., Synthesis, crystal structures and theoretical study of mixed ligand complexes of lanthanides acetylacetonates with o-phenanthroline and 2,2'-dipyridyl: The unexpected inverted electrostatic trend in stability. J. Mol. Struct. 2006, 789 (1), 187-194. 10.1016/j.molstruc.2005.12.026

60. Rogachev, A. Y.; Mironov, A. V.; Nemukhin, A. V., Experimental and theoretical studies of the products of reaction between $\mathrm{Ln}(\mathrm{hfa})_{3}$ and $\mathrm{Cu}(\mathrm{acac})_{2}(\mathrm{Ln}=\mathrm{La}, \mathrm{Y}$; acac $=$ acetylacetonate, $\mathrm{hfa}=\mathrm{hex}-$ afluoroacetyl-acetonate). J. Mol. Struct. 2007, 831 (1), 46-54. 10.1016/j.molstruc.2006.07.018

61. Ito, A.; Nakano, Y.; Urabe, M.; Tanaka, K.; Shiro, M. Structural and Magnetic Studies of Copper(II) and Zinc(II) Coordination Complexes Containing Nitroxide Radicals as Chelating Ligands. Eur. J. of Inorg. Chem. 2006, (17) 3359-3368. 10.1002/ejic.200600085

62. Gass, I.; Lu, J.; Ojha, R.; Asadi, M.; Lupton, D.; Geoghegan, B.; Moubaraki, B.; Martin, L.; Bond, A.; Murray, K. Austral. J. Chem. 2019, 72, 769, 10.1071/CH19175

63. Alvarez, S.; Alemany, P.; Casanova, D.; Cirera, J.; Llunell, M.; Avnir D. SHAPE 2.1 program for the stereochemical analysis of molecular fragments by means of continuous shape measures and associated tools.

64. Bussire, G.; Beaulac, R.; Blisle, H.; Lescop, Ch.; Luneau, D.; Rey, P.; Reber, Ch. Excited States and Optical Spectroscopy of Nitronyl Nitroxides and their Lanthanide and Transition Metal Complexes. In: Transition Metal and Rare Earth Compounds. Topics in Current Chemistry, vol 241. Springer, Berlin, Heidelberg. https://doi.org/10.1007/b96861

65. Ishida, T.; Murakami, R.; Kanetomo, T.; Nojiri, H. Magnetic study on radical-gadolinium(III) complexes. Relationship between the exchange coupling and coordination structure Polyhedron 2013, 66, 183-187. $10.1016 /$ j.poly.2013.04.004

66. Kanetomo, T.; Ishida, T. Strongest Exchange Coupling in Gadolinium(III) and Nitroxide Coordination Compounds Inorg. Chem. 2014, 53, 10794 10796 10.1021/ic501496a

67. P. Hu, Z. Sun, X. Wang, L. Li, D. Liao Magnetic relaxation in mononuclear Tb complex involving a nitronyl nitroxide ligand New J. Chem., 2014, 38 , 4716-4721. 10.1039/C4NJ00627E

68. Nakamura, T. Ishida, T. Magnetic exchange interaction in Gadolinium(III) complex having aliphatic nitroxide radical TEMPO. February 2016 AIP Conference Proceedings 1709(1):020016. 10.1063/1.4941215 Conference: Progress in Applied Mathematics in Science and Engineering Proceedings.

69. Caneschi, A.; Dei, A.; Gatteschi, D.; Sorace, L.; Vostrikova, K. Antiferromagnetic Coupling in a Gadolinium(III) Semiquinonato Complex. Angew. Chem., Int. Ed., 2000, 39 (1), 246-248. 10.1002/(SICI)15213773(20000103)39:1<246::AID-ANIE246>3.0.CO;2-B

70. Debye P. Zur Theorie der spezifischen Wärmen. Ann. Phys. (Leipzig) 1912, 344, 14, 789-839 10.1002/andp.19123441404

71. Tesi, L.; Lucaccini, E.; Cimatti, I.; Perfetti, M.; Mannini, M.; Atzori, M.; Morra, E.; Chiesa, M.; Caneschi, A.; Sorace, L.; Sessoli, R. Quantum coherence in a processable vanadyl complex: new tools for the search of molecular spin qubits. Chem. Sci., 2016, 7 (3), 2074-2083. 10.1039/c5sc04295j

72. Ito, A.; Nakano, Y.; Urabe, M.; Tanaka, K.; Shiro, M. Structural and Magnetic Studies of Copper(II) and Zinc(II) Coordination Complexes Containing Nitroxide Radicals as Chelating Ligands Eur. J. Inorg. Chem. 2006, (17), 3359-3368. 10.1002/ejic.200600085

73. APEX2, ver. 2.0; SAINT, ver. 8.18c; SADABS ver. 2.11; Bruker Advanced X-ray Solutions. Madison, Wisconsin, USA, 2000-2012.

74. Sheldrick, G., SHELXT - Integrated space-group and crystal-structure determination. Acta Crystallogr. Sect. A 2015, 71 (1), 3-8.

$10.1107 / \mathrm{S} 2053273314026370$

75. Sheldrick, G., Crystal structure refinement with SHELXL Acta Crystallogr. Sect. C 2015, 71 (1), 3-8. 10.1107/S2053229614024218

76. Dolomanov, O. V.; Bourhis, L. J.; Gildea, R. J.; Howard, J. A. K.;

Puschmann, H., OLEX2: a complete structure solution, refinement and analysis program. J. Appl. Crystallogr. 2009, 42 (2), 339-341.

$10.1107 /$ S0021889808042726

77. Bain, A.; Berry, J. F. Diamagnetic Corrections and Pascal's Constants Gordon J. Chem. Educ. 2008, 85 (4), 532-536. 10.1021/ed085p532 


\section{Supporting information on}

Table S1. Geometry analysis of the complexes by SHAPE software

\begin{tabular}{|c|c|c|c|}
\hline$\left[\operatorname{LnRad}\left(\mathrm{NO}_{3}\right)_{3}\right]$ & $\begin{array}{c}\mathrm{C}_{4 v}(\text { Spherical capped square } \\
\text { antiprism) }\end{array}$ & $\begin{array}{c}\mathrm{D}_{3 h}(\text { Spherical tricapped trigo- } \\
\text { nal prism) }\end{array}$ & $\mathrm{C}_{s}$ (Muffin) \\
\hline $\mathrm{Y}$ & 2.935 & 2.141 & 3.171 \\
\hline Dy & 3.025 & 2.220 & 3.256 \\
\hline $\mathrm{Tm}$ & 2.806 & 2.018 & 2.992 \\
\hline
\end{tabular}

Table S2. Bond lengths $(\AA)$ for the compounds $\left[\operatorname{LnRad}\left(\mathrm{NO}_{3}\right)_{3}\right](\mathrm{Ln}=\mathrm{Y}$, Dy, and Tm)

\begin{tabular}{|c|c|c|c|c|c|c|c|c|}
\hline \multicolumn{3}{|c|}{ Dy } & \multicolumn{3}{|c|}{$\mathbf{T m}$} & \multicolumn{3}{|c|}{$\mathbf{Y}$} \\
\hline Atom & Atom & Length & Atom & Atom & Length & Atom & Atom & Length \\
\hline Dy1 & $\mathrm{O} 11$ & $2.3838(16)$ & Tm1 & $\mathrm{O} 11$ & $2.349(3)$ & Y1 & O11 & $2.3720(12)$ \\
\hline Dy1 & $\mathrm{O} 21$ & $2.4130(19)$ & Tm1 & $\mathrm{O} 21$ & $2.386(3)$ & Y1 & $\mathrm{O} 21$ & $2.4369(14)$ \\
\hline Dy1 & $\mathrm{O} 22$ & $2.4452(19)$ & Tm1 & $\mathrm{O} 22$ & $2.409(3)$ & Y1 & $\mathrm{O} 22$ & $2.3883(13)$ \\
\hline Dy1 & $\mathrm{O} 31$ & $2.448(2)$ & Tm1 & $\mathrm{O} 31$ & $2.386(3)$ & Y1 & $\mathrm{O} 31$ & $2.4314(14)$ \\
\hline Dy1 & $\mathrm{O} 32$ & $2.3892(18)$ & Tm1 & $\mathrm{O} 32$ & $2.374(3)$ & Y1 & $\mathrm{O} 32$ & $2.4087(13)$ \\
\hline Dy1 & O41 & $2.4016(18)$ & Tm1 & $\mathrm{O} 41$ & $2.362(3)$ & Y1 & $\mathrm{O} 41$ & $2.3915(14)$ \\
\hline Dy1 & O42 & $2.4249(18)$ & Tm1 & $\mathrm{O} 42$ & $2.414(3)$ & Y1 & $\mathrm{O} 42$ & $2.4124(13)$ \\
\hline Dy1 & N11 & $2.5008(18)$ & Tm1 & N11 & $2.460(3)$ & Y1 & N12 & $2.4934(14)$ \\
\hline Dy1 & N12 & $2.5006(19)$ & Tm1 & N12 & $2.463(3)$ & Y1 & N13 & $2.4985(14)$ \\
\hline O11 & N13 & $1.276(2)$ & O11 & N13 & $1.272(4)$ & O11 & N11 & $1.2766(17)$ \\
\hline $\mathrm{O} 12$ & $\mathrm{C} 110$ & $1.400(3)$ & $\mathrm{O} 12$ & C110 & $1.405(4)$ & $\mathrm{O} 12$ & C110 & $1.4049(19)$ \\
\hline $\mathrm{O} 12$ & C111 & $1.434(3)$ & $\mathrm{O} 12$ & C111 & $1.433(5)$ & 012 & C111 & $1.439(2)$ \\
\hline $\mathrm{O} 21$ & $\mathrm{~N} 2$ & $1.269(3)$ & $\mathrm{O} 21$ & $\mathrm{~N} 21$ & $1.280(5)$ & $\mathrm{O} 21$ & $\mathrm{~N} 21$ & $1.272(2)$ \\
\hline $\mathrm{O} 22$ & $\mathrm{~N} 2$ & $1.264(3)$ & $\mathrm{O} 22$ & $\mathrm{~N} 21$ & $1.264(5)$ & $\mathrm{O} 22$ & $\mathrm{~N} 21$ & $1.2690(19)$ \\
\hline $\mathrm{O} 23$ & $\mathrm{~N} 2$ & $1.206(3)$ & $\mathrm{O} 23$ & N21 & $1.210(5)$ & $\mathrm{O} 23$ & $\mathrm{~N} 21$ & $1.210(2)$ \\
\hline O31 & N3 & $1.262(3)$ & $\mathrm{O} 31$ & N31 & $1.262(5)$ & O31 & N31 & $1.273(2)$ \\
\hline O32 & N3 & $1.273(3)$ & $\mathrm{O} 32$ & N31 & $1.270(5)$ & $\mathrm{O} 32$ & N31 & $1.269(2)$ \\
\hline $\mathrm{O} 33$ & N3 & $1.205(3)$ & $\mathrm{O} 33$ & N31 & $1.209(5)$ & $\mathrm{O} 33$ & N31 & $1.215(2)$ \\
\hline O41 & $\mathrm{N} 4$ & $1.271(3)$ & $\mathrm{O} 41$ & N41 & $1.272(5)$ & O41 & N41 & $1.2670(19)$ \\
\hline $\mathrm{O} 42$ & N4 & $1.260(3)$ & $\mathrm{O} 42$ & N41 & $1.266(5)$ & O42 & $\mathrm{N} 41$ & $1.267(2)$ \\
\hline O43 & $\mathrm{N} 4$ & $1.213(3)$ & $\mathrm{O} 43$ & N41 & $1.205(5)$ & O43 & N41 & $1.2169(19)$ \\
\hline N11 & $\mathrm{C} 120$ & $1.342(3)$ & N11 & C115 & $1.341(5)$ & N11 & C110 & $1.485(2)$ \\
\hline N11 & $\mathrm{C} 124$ & $1.340(3)$ & N11 & C119 & $1.334(5)$ & N11 & C112 & $1.484(2)$ \\
\hline N12 & C115 & $1.349(3)$ & N12 & C120 & $1.353(5)$ & $\mathrm{N} 12$ & C115 & $1.340(2)$ \\
\hline N12 & C119 & $1.342(3)$ & N12 & C124 & $1.339(5)$ & N12 & C119 & $1.347(2)$ \\
\hline N13 & $\mathrm{C} 110$ & $1.487(3)$ & N13 & C110 & $1.477(5)$ & N13 & $\mathrm{C} 120$ & $1.349(2)$ \\
\hline N13 & C112 & $1.481(3)$ & N13 & C112 & $1.488(5)$ & N13 & C124 & $1.346(2)$ \\
\hline $\mathrm{C} 110$ & C115 & $1.524(3)$ & $\mathrm{C} 110$ & C115 & $1.525(6)$ & C110 & C115 & $1.528(3)$ \\
\hline C110 & $\mathrm{C} 120$ & $1.530(3)$ & $\mathrm{C} 110$ & $\mathrm{C} 120$ & $1.522(5)$ & C110 & C120 & $1.529(2)$ \\
\hline C111 & C112 & $1.525(3)$ & C111 & C112 & $1.524(6)$ & C111 & C112 & $1.525(3)$ \\
\hline C112 & $\mathrm{C} 113$ & $1.526(3)$ & $\mathrm{C} 112$ & C113 & $1.524(6)$ & C112 & C113 & $1.508(3)$ \\
\hline C112 & C114 & $1.509(4)$ & C112 & C114 & $1.502(6)$ & C112 & C114 & $1.523(3)$ \\
\hline C115 & C116 & $1.379(3)$ & C115 & C116 & $1.381(6)$ & C115 & C116 & $1.385(2)$ \\
\hline C116 & C117 & $1.380(4)$ & C116 & C117 & $1.376(6)$ & C116 & C117 & $1.374(3)$ \\
\hline C117 & C118 & $1.373(4)$ & C117 & C118 & $1.362(7)$ & C117 & C118 & $1.375(3)$ \\
\hline C118 & C119 & $1.375(4)$ & C118 & C119 & $1.385(6)$ & C118 & C119 & $1.377(3)$ \\
\hline C120 & $\mathrm{C} 121$ & $1.380(3)$ & $\mathrm{C} 120$ & C121 & $1.372(6)$ & C120 & C121 & $1.379(2)$ \\
\hline C121 & C122 & $1.373(4)$ & C121 & C122 & $1.375(7)$ & C121 & C122 & $1.384(3)$ \\
\hline $\mathrm{C} 122$ & $\mathrm{C} 123$ & $1.379(4)$ & $\mathrm{C} 122$ & C123 & $1.368(7)$ & C122 & C123 & $1.371(3)$ \\
\hline $\mathrm{C} 123$ & $\mathrm{C} 124$ & $1.377(4)$ & $\mathrm{C} 123$ & C124 & $1.381(6)$ & C123 & C124 & $1.375(3)$ \\
\hline
\end{tabular}


Table S3. Crystallographic data and refinement details for the compounds $\left[\operatorname{LnRad}\left(\mathrm{NO}_{3}\right)_{3}\right](\mathrm{Ln}=\mathrm{Y}, \mathrm{Dy}, \mathrm{Tm})$.

\begin{tabular}{|c|c|c|c|}
\hline Identification code & Dy & $\mathbf{T m}$ & $\mathbf{Y}$ \\
\hline Empirical formula & $\mathrm{C}_{15} \mathrm{H}_{16} \mathrm{DyN}_{6} \mathrm{O}_{11}$ & $\mathrm{C}_{15} \mathrm{H}_{16} \mathrm{~N}_{6} \mathrm{O}_{11} \mathrm{Tm}$ & $\mathrm{C}_{15} \mathrm{H}_{16} \mathrm{~N}_{6} \mathrm{O}_{11} \mathrm{Y}$ \\
\hline Formula weight & 618.84 & 625.27 & 545.25 \\
\hline Space group & $P 2_{1} / n$ & $P 2_{1} / n$ & $P 2_{1} / n$ \\
\hline $\mathrm{a} / \AA ̊$ & $10.0634(3)$ & $10.0090(7)$ & $10.0666(2)$ \\
\hline $\mathrm{b} / \AA \AA$ & $16.6299(5)$ & $16.5894(10)$ & $16.6513(5)$ \\
\hline $\mathrm{c} / \AA$ & $12.9513(4)$ & $12.9462(8)$ & $13.0062(3)$ \\
\hline$\beta /{ }^{\circ}$ & $104.2850(10)$ & $104.054(2)$ & $104.1540(10)$ \\
\hline Volume $/ \AA^{3}$ & $2100.43(11)$ & $2085.3(2)$ & 2113.94(9) \\
\hline $\mathrm{Z}$ & 4 & 4 & 4 \\
\hline$\rho_{\text {calc }} \mathrm{g} / \mathrm{cm}^{3}$ & 1.957 & 1.992 & 1.713 \\
\hline$\mu / \mathrm{mm}^{-1}$ & 3.629 & 4.327 & 2.830 \\
\hline $\mathrm{F}(000)$ & 1208.0 & 1220.0 & 1100.0 \\
\hline Crystal size $/ \mathrm{mm}^{3}$ & $0.2 \times 0.2 \times 0.15$ & $0.35 \times 0.08 \times 0.05$ & $0.4 \times 0.3 \times 0.25$ \\
\hline $2 \Theta$ range for data collection $/{ }^{\circ}$ & 4.066 to 51.418 & 4.068 to 51.428 & 4.052 to 51.434 \\
\hline Index ranges & $\begin{array}{l}-12 \leq \mathrm{h} \leq 12 \\
-20 \leq \mathrm{k} \leq 20,-14 \leq 1 \leq 15\end{array}$ & $\begin{array}{l}-11 \leq \mathrm{h} \leq 12 \\
-20 \leq \mathrm{k} \leq 20,-15 \leq 1 \leq 13\end{array}$ & $\begin{array}{l}-12 \leq \mathrm{h} \leq 12 \\
-20 \leq \mathrm{k} \leq 20,-15 \leq 1 \leq 15\end{array}$ \\
\hline Reflections collected & 21835 & 22434 & 25989 \\
\hline Independent reflections & $\begin{array}{l}3989\left[R_{\text {int }}=0.0298,\right. \\
\left.R_{\text {sigma }}=0.0204\right]\end{array}$ & $\begin{array}{l}3962\left[R_{\text {int }}=0.0275,\right. \\
\left.R_{\text {sigma }}=0.0173\right]\end{array}$ & $\begin{array}{l}4011\left[R_{\text {int }}=0.0326,\right. \\
\left.R_{\text {sigma }}=0.0209\right]\end{array}$ \\
\hline Restraints/parameters & $0 / 300$ & $0 / 300$ & $0 / 300$ \\
\hline Goodness-of-fit on $\mathrm{F}^{2}$ & 1.060 & 1.118 & 1.065 \\
\hline Final $\mathrm{R}$ indexes $[\mathrm{I}>=2 \sigma(\mathrm{I})]$ & $\mathrm{R}_{1}=0.0184, \mathrm{wR}_{2}=0.0472$ & $\mathrm{R}_{1}=0.0251, \mathrm{wR}_{2}=0.0697$ & $\mathrm{R}_{1}=0.0220, \mathrm{wR}_{2}=0.0530$ \\
\hline Final $\mathrm{R}$ indexes [all data] & $\mathrm{R}_{1}=0.0197, \mathrm{wR}_{2}=0.0482$ & $\mathrm{R}_{1}=0.0266, \mathrm{wR}_{2}=0.0710$ & $\mathrm{R}_{1}=0.0276, \mathrm{wR}_{2}=0.0550$ \\
\hline Largest diff. peak/hole / e $\AA^{-3}$ & $0.89 /-0.56$ & $2.58 /-0.51$ & $0.24 /-0.23$ \\
\hline
\end{tabular}

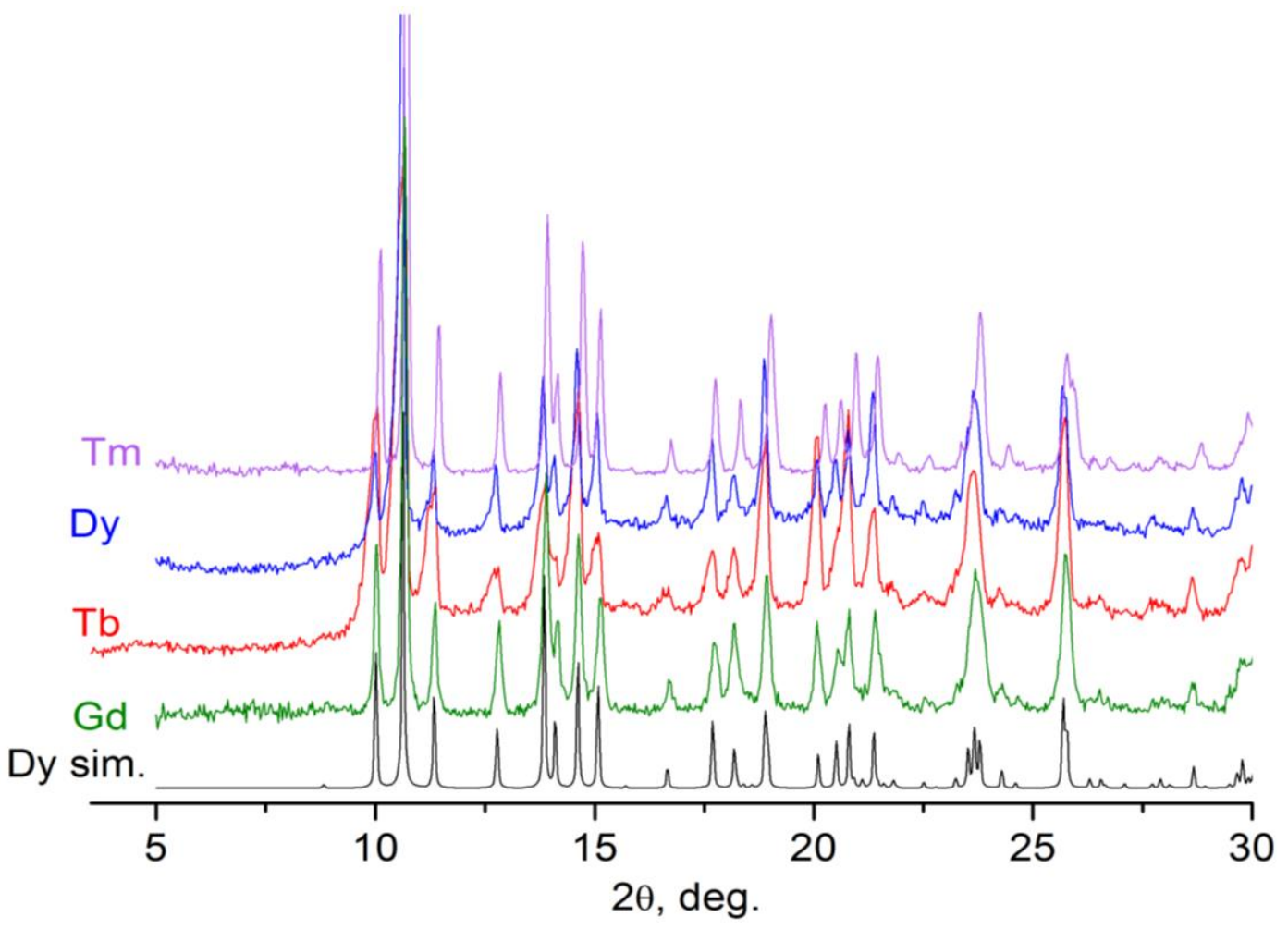

Figure S1. Simulated (black) and experimental (colored) powder patterns of the compounds $\left[\mathrm{LnRad}\left(\mathrm{NO}_{3}\right)_{3}\right]$. 


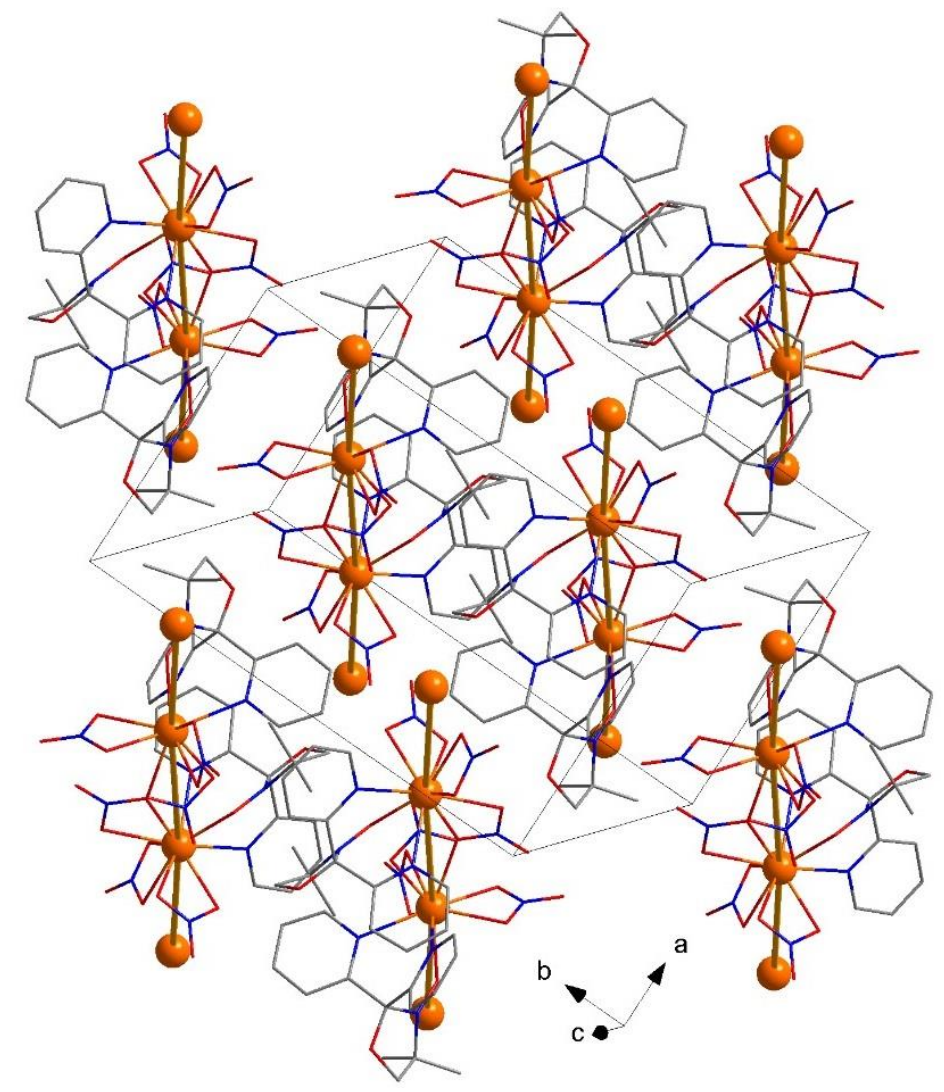

Figure S2. A fragment of the crystal packing of $\left[\operatorname{LnRad}\left(\mathrm{NO}_{3}\right)_{3}\right](\mathrm{Ln}=\mathrm{Y}$, Dy, Tm). The shortest $\mathrm{Ln} \cdots \operatorname{Ln}$ distances are highlighted by orange lines.
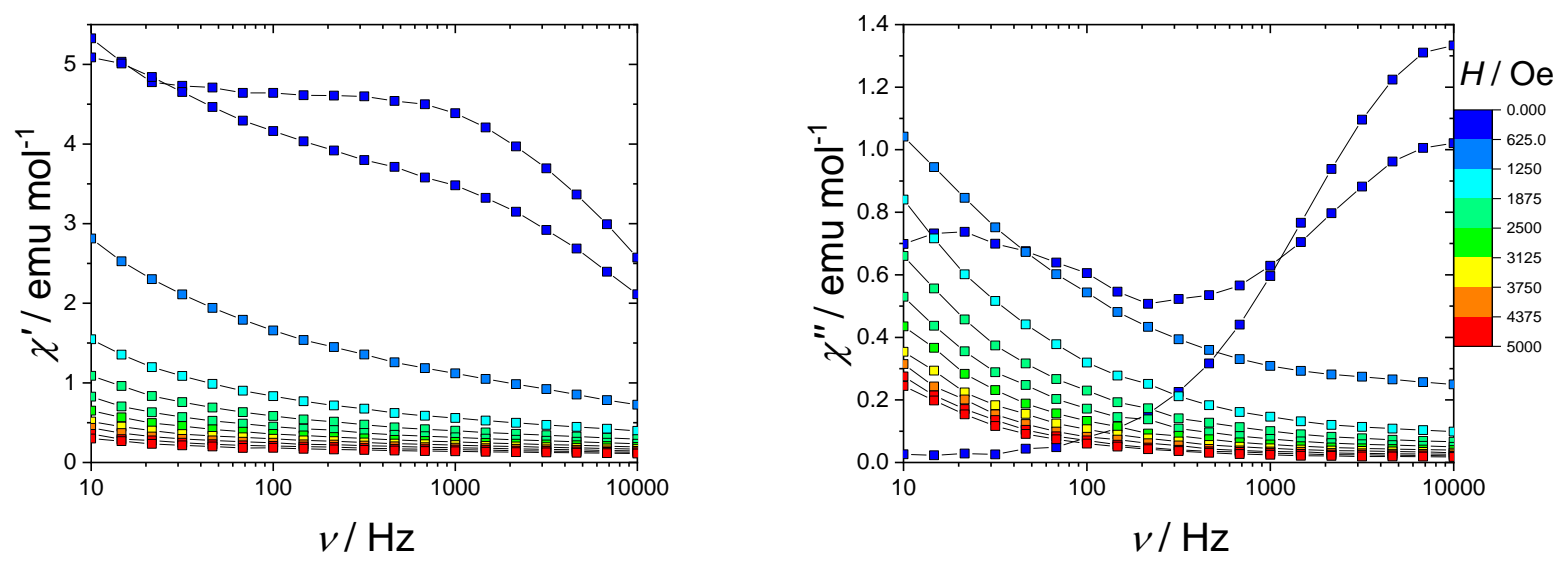

Figure S3. Real (left) and Imaginary (right) components of the ac susceptibility of $\left[\mathrm{TbRad}\left(\mathrm{NO}_{3}\right)_{3}\right]$ measured at $T=2 \mathrm{~K}$ and different fields. 

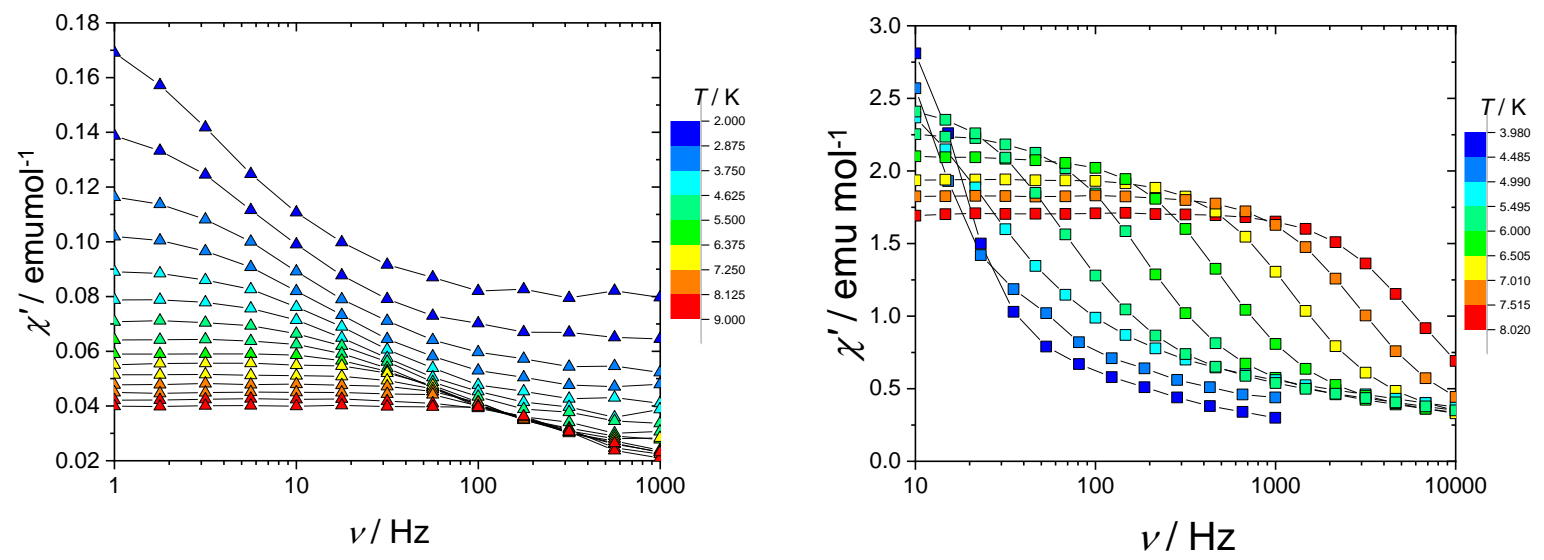

Figure S4. Real component of the ac susceptibility of $\left[\mathrm{TbRad}\left(\mathrm{NO}_{3}\right)_{3}\right]$ measured at $B=1000$ Oe and different temperatures.

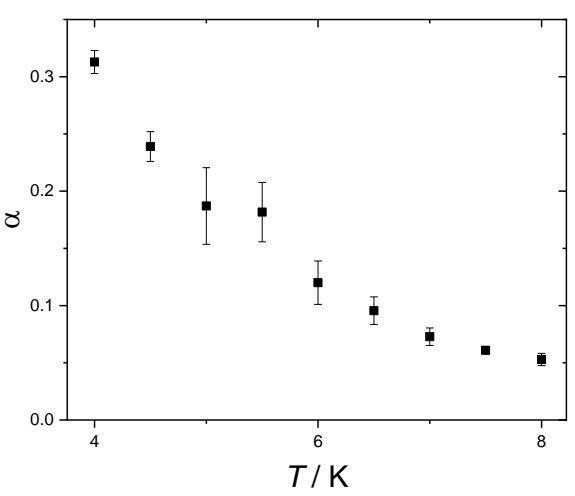

Figure S5. Debye distribution widths for $\left[\mathrm{TbRad}\left(\mathrm{NO}_{3}\right)_{3}\right]$.

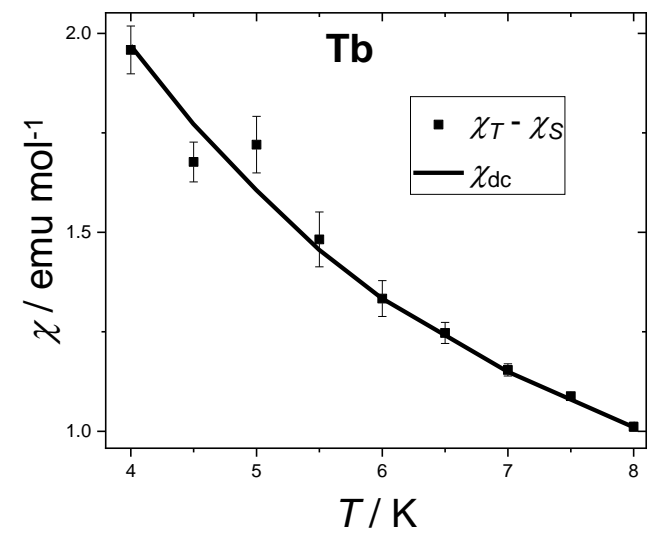

Figure S6. Comparison of the dc magnetic susceptibility with the $\chi_{\mathrm{T}-} \chi_{\mathrm{S}}$ values extracted from the ac fit $\left[\operatorname{TbRad}\left(\mathrm{NO}_{3}\right)_{3}\right]$. 